\title{
Seroprevalencia del Virus de la Rinoneumonitis en Caballos (Equus caballus) del Perú
}

\author{
Seroprevalence of Rhinopneumonitis Virus in Horses from Peru \\ David Galindo H. ${ }^{1}$, Hermelinda Rivera G. ${ }^{1,3}$, Mercy Ramírez V. ${ }^{1}$, \\ Juan More B. ${ }^{1}$, Alberto Manchego S. ${ }^{1}$, Jorge Mantilla S. ${ }^{2}$, William Valderrama B. ${ }^{2}$
}

\section{Resumen}

El objetivo del presente estudio fue determinar la seroprevalencia del virus Herpes Equino tipo 1 o Herpes Equino tipo 4(VHE-1/VHE-4), causante de la rinoneumonitis viral en caballos. Se recolectaron muestras de suero $(n=825)$ de caballos mayores a seis meses de edad, entre machos y hembras, identificados como caballos de crianza familiar, de carrera, Peruano de Paso y de equitación, clínicamente normales, provenientes de varias regiones del Perú, para la detección de anticuerpos neutralizantes contra el VHE-1/ VHE-4 mediante la prueba de neutralización viral. El 48.9 $\pm 5.3 \%$ (403/825) de las muestras tuvieron anticuerpos contra el VHE-1/VHE-4. Los títulos de anticuerpos tuvieron un rango entre 2 a $>256$, siendo de $58.6 \%$ de títulos de 2 a 8 , de $29.5 \%$ en títulos de 16 a 64 , y de $11.9 \%$ en títulos de 128 a $>256$. La prueba de regresión logística indicó que las variables sexo y lugar de procedencia no constituyeron factores de riesgo para la presentación de anticuerpos contra el VHE-1/VHE-4.

Palabras clave: caballo, rinoneumonitis equina, virus herpes equino tipo 1 , herpes equino tipo 4, anticuerpos, neutralización viral

\section{Abstract}

The aim of this study was to determine the seroprevalence of antibodies against Equine Herpes Virus type 1 (EHV-1) and Equine Herpes Virus type 4 (EHV-4), which causes rhinopneumonitis in horses. Blood samples $(n=825)$ from Peruvian horses older than six months of age, both sexes, identified as racehorses, Peruvian Paso, equitation and criollo, in apparent healthy conditions, were collected for detection of neutralizing

\footnotetext{
${ }^{1}$ Laboratorio de Microbiología y Parasitología Veterinaria, Facultad de Medicina Veterinaria, Universidad Nacional Mayor de San Marcos, Lima, Perú

${ }^{2}$ Dirección de Análisis de Riesgo y Vigilancia Epidemiológica, Servicio Nacional de Sanidad Agraria (SENASA), Lima, Perú

${ }^{3}$ E-mail: hriverag2010@gmail.com
}

Recibido: 11 de setiembre de 2014

Aceptado para publicación: 30 de diciembre de 2014 
antibodies against EHV-1/EHV-4 by virus neutralization test. The $48.9 \pm 5.3 \%(403 / 825)$ of the samples had antibodies against EHV-1/EHV-4. Antibody titers ranged from 2 to $>256$, where $58.5 \%$ ranged from 2 to $8,29.5 \%$ from 16 to 64 , and $11.9 \%$ from 128 to $>256$. The sex and region of the country did not represent a risk for presenting antibodies against EHV-1/EHV-4.

Key words: horse, equine rhinopneumonitis, equine herpes virus type 1, equine herpes virus type 4 , antibodies, virus neutralization

\section{INTRODUCCIÓN}

El Perú cuenta con una población de 1260219 équidos de las cuales 597969 son caballos (Equus caballus) y la diferencia corresponde a burros y mulas (INEI, 2012). La población de caballos comprende caballos criollos o de crianza familiar que son utilizados como medio de transporte, en labores agrícolas, etc., y los caballos de raza dedicados a actividades deportivas o de exhibición, como el Caballo Peruano de Paso, de equitación, carrera, etc. Al igual que en otros países, el caballo cumple diversos roles en el aspecto social, pecuario y económico (Goodwin, 1999; Gordon, 2001).

El caballo, como toda especie animal, es susceptible a infecciones por agentes bacterianos o virales, que pueden afectar al sistema respiratorio, reproductivo o nervioso, entre otros. Algunos de estos agentes virales son los virus herpes equino tipo 1 (VHE-1) y virus herpes equino tipo 4 (VHE-4), causantes de la rinoneumonitis equina (RNE) y pérdidas fetales. La RNE es un término colectivo que refiere a una enfermedad clínica aguda o subclínica causada por el VHE-1 o VHE-4, pues ambos virus pueden infectar al tracto respiratorio. La RNE es una de las enfermedades virales de mayor importancia en la producción equina mundial, debido a las pérdidas económicas que ocasiona (Boelaert et al., 2000; Ploszay et al., 2013).

Los VHE-1/VHE-4 son miembros del género Varicellovirus de la subfamilia Alfa- herpesvirinae, familia Herpesviridae (Johnson y Baines, 2011). El VHE-1 y el VHE-4 son dos agentes virales inmunológicamente relacionados, aunque molecularmente diferentes, que afectan a los caballos domésticos de todas las edades y razas a nivel mundial (OIE, 2008). El VHE-1 es el principal causante de abortos, muerte temprana de neonatos, problemas respiratorios y mieloencefalopatías (Patel y Heldens, 2005; Pusterla et al., 2009). Aunque la ocurrencia de la mieloencefalopatía por VHE-1 es esporádica y de manifestación poco común, puede causar pérdidas severas, como lo ocurrido recientemente en escuelas de equitación, hipódromos y hospitales veterinarios en Norteamérica y Europa (Henninger et al., 2007; Pusterla et al., 2009). Por otro lado, el virus VHE-4 es el agente primario de procesos respiratorios, caracterizados por rinofaringitis, traqueobronquitis y, ocasionalmente, es causante de abortos (Ellis et al., 1995; Ploszay et al., 2013).

En el Perú, la RNE fue reportada por aislamiento viral durante brotes de abortos en caballos de carrera (Rivera et al., 1997) y serología en caballos, principalmente de la costa (Ríos et al., 2002). Dado que la infección por VHE-1/VHE-4 puede ser de tipo subclínico y no es restrictiva para el movimiento interno de los caballos, la infección podría estar distribuida a nivel nacional, por lo que el presente estudio tuvo por objetivo determinar la seroprevalencia de los virus VHE-1/VHE-4, causantes de la rinoneumonitis equina en caballos del país. 


\section{Materiales y Métodos}

\section{Muestras de Suero}

El Servicio Nacional de Sanidad Agraria (SENASA) del Perú, zonifica los departamentos del Perú como A, B y C. Es así que aquellos de la zona A están ubicados en la costa y no tienen frontera, los de la zona $\mathrm{B}$ tienen frontera $\mathrm{y}$ los de la zona $\mathrm{C}$ no tienen frontera y no están en la costa (SENASA, 2013).

Se utilizaron 825 muestras de suero de caballos entre machos $(n=451)$ y hembras $(n=374)$, mayores a seis meses de edad, identificados como caballos de crianza familiar (criollos), Caballo Peruano de Paso, de carrera, de equitación (deporte) y sin especificar. Los caballos provenían de todos los departamentos de la zonas $\mathrm{A}(\mathrm{n}=145), \mathrm{B}(\mathrm{n}=310)$ y $C(n=370)$. Las muestras fueron colectadas en el periodo 2011-2012 por el SENASA.

\section{Tamaño de Muestra}

El tamaño mínimo de muestra fue obtenido mediante la fórmula para muestreo por conglomerado en multi-etapas (Segura y Honhold, 2000). Un muestreo por conglomerados se obtiene midiendo algunos de sus elementos para obtener una muestra probabilística del conglomerado. Este tipo de tamaño de muestra suele incrementar el error estándar entre dos y cuatro veces, por lo que se requiere una muestra entre dos y cuatro veces más grande que el tamaño obtenido para un muestreo simple al azar.

\section{Cepa Viral (Antígeno)}

Se utilizó la cepa vacunal Rhinomune HVE-1 (Herpes Virus Equino tipo-1), donada por el Dr. Robert Ellis (EEUU), como antígeno en la prueba de neutralización viral con un título de $10^{-5} \mathrm{DL}_{50} \mathrm{CC} / 50 \mu \mathrm{l}$.

\section{Detección de Anticuerpos}

La detección de anticuerpos contra el VHE-1/VHE-4 fue realizado mediante la prueba de neutralización viral según el protocolo descrito por la Organización Mundial de Sanidad Animal (OIE, 2008), y disponible en la Sección de Virología de la Facultad de Medicina Veterinaria de la Universidad Nacional Mayor de San Marcos, Lima.

Una muestra de suero capaz de neutralizar el $100 \%$ de la capacidad infectante del virus en la monocapa celular fue considerada positiva a anticuerpos contra el virus y una muestra fue considerada negativa a anticuerpos cuando se observó $100 \%$ de efecto citopático en la monocapa celular.

\section{Análisis de Datos}

La seroprevalencia del VHE-1/VHE-4 fue determinada mediante la fórmula descrita por Segura y Honhold (2000) y expresada en porcentaje con intervalo de confianza del 95\% (Daniel, 1996). Las asociaciones entre la variable presencia o ausencia de anticuerpos contra VHE-1/VHE-4 y las variables sexo y lugar de procedencia fueron determinadas mediante la prueba de Regresión Logística empleando el Programa Estadístico y Análisis de Datos STATA v. 12. La variable tipo de actividad de los caballos no fue considerada como una variable válida para el análisis ante la imposibilidad de diferenciar anticuerpos vacunales de los inducidos por virus de campo en los caballos Peruano de Paso, de carrera y de equitación.

\section{Resultados}

La seroprevalencia del VHE-1/VHE-4 detectada en las muestras de caballos a nivel nacional fue $48.9 \pm 3.4 \%$ (403/825). Se pudo detectar anticuerpos en caballos de prácticamente todos los departamentos del país (Cuadro 1). 
Cuadro 1. Seroprevalencia del virus Herpes Equino-1/Herpes Equino-4 en caballos de los departamentos, según zonas del Perú (2011-2012)

\begin{tabular}{|c|c|c|c|c|}
\hline \multirow[t]{2}{*}{ Zona } & \multirow[t]{2}{*}{ Departamento } & \multirow{2}{*}{$\begin{array}{l}\text { Animales } \\
\left(\mathrm{N} .^{\circ}\right)\end{array}$} & \multicolumn{2}{|c|}{$\begin{array}{c}\text { Positivos a anticuerpos contra } \\
\text { VHE-1/VHE-4 }\end{array}$} \\
\hline & & & $\mathrm{n}$ & $\% \pm \mathrm{IC}^{1}$ \\
\hline \multirow[t]{8}{*}{ A } & Ancash & 40 & 30 & $75.0 \pm 3.4$ \\
\hline & Arequipa & 15 & 3 & $20.0 \pm 20.2$ \\
\hline & Ica & 10 & 7 & $70.0 \pm 28.4$ \\
\hline & La Libertad & 30 & 22 & $73.3 \pm 15.8$ \\
\hline & Lambayeque & 15 & 5 & $33.3 \pm 23.9$ \\
\hline & Lima-Callao & 30 & 27 & $90.0 \pm 10.7$ \\
\hline & Moquegua & 5 & 4 & $80.0 \pm 35.1$ \\
\hline & Sub-total & 145 & 98 & $67.9 \pm 7.6$ \\
\hline \multirow[t]{10}{*}{$\mathrm{B}$} & Amazonas & 35 & 18 & $51.4 \pm 16.6$ \\
\hline & Cajamarca & 130 & 53 & $40.8 \pm 8.4$ \\
\hline & Loreto & 5 & 1 & $20.0 \pm 35.1$ \\
\hline & Madre de Dios & 5 & 0 & 0 \\
\hline & Piura & 80 & 30 & $37.5 \pm 10.6$ \\
\hline & Puno & 40 & 29 & $72.5 \pm 13.8$ \\
\hline & Ucayali & 5 & 2 & $40.0 \pm 42.9$ \\
\hline & Tacna & 5 & 5 & 100.0 \\
\hline & Tumbes & 5 & 2 & $40.0 \pm 42.9$ \\
\hline & Sub-total & 310 & 140 & $45.2 \pm 5.5$ \\
\hline \multirow[t]{9}{*}{$\mathrm{C}$} & Apurímac & 75 & 34 & $45.3 \pm 11.3$ \\
\hline & Ayacucho & 40 & 16 & $40.0 \pm 15.2$ \\
\hline & Cerro de Pasco & 15 & 10 & $66.7 \pm 23.9$ \\
\hline & Cusco & 85 & 14 & $16.5 \pm 7.9$ \\
\hline & Huancave lica & 50 & 38 & $76.0 \pm 11.8$ \\
\hline & Huánuco & 45 & 26 & $57.8 \pm 14.4$ \\
\hline & Junín & 20 & 19 & $95.0 \pm 9.6$ \\
\hline & San Martín & 40 & 8 & $20.0 \pm 12.4$ \\
\hline & Sub-total & 370 & 165 & $44.6 \pm 5.1$ \\
\hline Total & & 825 & 403 & $48.9 \pm 3.4$ \\
\hline
\end{tabular}

${ }^{1}$ Intervalo de confianza del $95 \%$ 
Cuadro 2. Seroprevalencia del virus Herpes Equino-1/virus Herpes Equino-4 en caballos, según tipo de actividad (2011-2012)

\begin{tabular}{lccc}
\hline & Animales & \multicolumn{2}{c}{$\begin{array}{c}\text { Positivos a anticuerpos contra } \\
\text { VHE-1/VHE-4 }\end{array}$} \\
\cline { 3 - 4 } & $\left(\mathrm{N}^{\circ}{ }^{\circ}\right.$ & $\mathrm{n}$ & $\% \pm \mathrm{IC}^{1}$ \\
\hline Caballo criollo & 670 & 324 & $48.3 \pm 3.8$ \\
Caballo Peruano de Paso & 92 & 41 & $44.7 \pm 10.2$ \\
Caballo de carrera & 30 & 27 & $90.0 \pm 10.7$ \\
Caballo de equitación & 15 & 10 & $66.7 \pm 23.9$ \\
Sin especificar & 18 & 1 & $5.5 \pm 10.5$ \\
\hline Total & 825 & 403 & $48.9 \pm 3.4$ \\
\hline
\end{tabular}

${ }^{1}$ Intervalo de confianza del $95 \%$

Cuadro 3. Distribución de los títulos de anticuerpos neutralizantes contra el virus Herpes Equino-1/virus Herpes Equino-4 en caballos, según tipo de actividad (2011-2012)

\begin{tabular}{lcccccc}
\hline & \multicolumn{6}{c}{ Títulos de anticuerpos $^{1}$} \\
\cline { 2 - 8 } Tipo de actividad & \multicolumn{2}{c}{$2-8$} & \multicolumn{2}{c}{$16-64$} & \multicolumn{2}{c}{$128->256$} \\
\cline { 2 - 8 } & $\mathrm{n}$ & $\%$ & $\mathrm{n}$ & $\%$ & $\mathrm{n}$ & $\%$ \\
\hline Caballo criollo & 188 & 46.6 & 94 & 23.3 & 42 & 10.4 \\
Caballo Peruano de Paso & 26 & 6.5 & 11 & 2.7 & 4 & 1.0 \\
Caballo de carrera & 9 & 2.2 & 16 & 4.0 & 2 & 0.5 \\
Caballo de equitación & 7 & 1.7 & 3 & 0.8 & 0 & 0.0 \\
Sin especificar & 1 & 0.3 & 0 & 0.0 & 0 & 0.0 \\
\hline Total & 231 & 57.3 & 124 & 30.8 & 48 & 11.9 \\
\hline
\end{tabular}

${ }^{1}$ Inversa de la dilución 
En el Cuadro 2 se presentan los resultados de seroprevalencia, según tipo de actividad de los caballos. Los títulos de anticuerpos tuvieron un rango entre $2 \mathrm{a}>256$. El 58.6\% de los animales tuvieron títulos bajos entre 2 a 8 , el $29.5 \%$ de 16 a 64 y el $11.9 \%$ entre 128 a $>256$ (Cuadro 3).

El análisis de regresión logística indicó que las variables sexo y lugar de procedencia no afectaron la presencia de anticuerpos contra el virus.

\section{Discusión}

Los resultados del presente estudio indican que el VHE-1/VHE-4 está presente en el $48.9 \pm 3.4 \%$ de la población de caballos del país. La seroprevalencia detectada involucra ambos sexos y departamentos por igual, indicando que la infección viral está ampliamente difundida en la población de caballos en el país (Cuadro 1). En un estudio previo en caballos de carrera, equitación y caballos Peruano de Paso de la provincia de Lima se obtuvo una seroprevalencia similar (44.2\%) (Ríos et al., 2002).

En caballos de municipios del noreste de la ciudad de São Paulo se reportó una seroprevalencia de 27.2\% (Cunha et al., 2002), en caballos del Valle de Aburrá y Oriente cercano a Antioquia, Colombia, se encontró 98.7 y $96.6 \%$ para VHE-1 y VHE-4, respectivamente, utilizando la prueba de ELISA (Ruíz Sáenz et al., 2008). Así mismo, se han llevado a cabo estudios de prevalencia del virus herpes equino en países como Argentina (Galosi et al., 1998) y Chile (Berrios et $a l ., 2002)$ con similares resultados.

La amplia distribución del VHE-1/ VHE-4 en la población de caballos del país podría deberse, en parte, al libre movimiento interno de caballos, ya que este virus no es restrictivo para el movimiento de los équidos en general. Además, se debe considerar el carácter subclínico de la enfermedad en ca- ballos adultos (Goodman et al., 2012). Como en toda infección herpética, luego de la infección primaria, el virus puede permanecer en estado de latencia en el ganglio trigémino, en el tejido linforeticular y en los leucocitos en casi el 80\% de los caballos, aunque estos animales se encuentran en un estado fisiológicamente normal (Borchers et al., 1999). Sin embargo, bajo condiciones de estrés como el transporte, desnutrición, parasitismo, preñez, etc., el virus puede reactivarse e infectar a otros caballos, y así mantenerse en la población (Walter et al., 2013).

Pese a su amplia distribución en los caballos del país, existen escasos reportes sobre la ocurrencia de casos clínicos compatibles con rinoneumonitis equina o aborto equino. Clínicamente, brotes de problemas respiratorios son frecuentes en animales jóvenes en los haras de Lima (R. Oballe, Lima, comunicación personal), pero no se han realizado estudios para determinar la participación del VHE-1/VHE-4 en estos procesos respiratorios. Solo existe un reporte de un brote de abortos por este virus, donde el $76 \%$ (13/17) de la yeguas abortaron en un corto periodo de tiempo (Rivera et al., 1997). Usualmente, la prevalencia o incidencia de los abortos en caballos es poco conocida, probablemente, porque los fetos equinos abortados no son enviados a los laboratorios para su diagnóstico por problemas de logística, costos, etc. (Maanen et al., 2000).

Los anticuerpos neutralizantes detectados en los caballos pudieron haber sido inducidos por infecciones naturales o por vacunaciones contra la RNE, ya que la prueba de neutralización viral no discrimina entre anticuerpos inducidos por virus de campo o por vacuna (Van Oirschot et al., 1996). No obstante, los anticuerpos detectados en los caballos criollos fueron inducidos por virus de campo, ya que, usualmente, estos animales no reciben vacunación contra el VHE-1/ VHE-4 u otras enfermedades virales. Algunos criadores de caballos dedicados a actividades de exhibición o deporte, como los caballos de carrera y los caballos Peruano de 
Paso, indican que vacunan contra el VHE-1/ VHE-4 para prevenir problemas respiratorios en los animales jóvenes y abortos en las yeguas. Es así, que los anticuerpos detectados en estos caballos podrían ser de origen vacunal como lo indica la seropositividad detectada en estos animales. Además, los títulos de los anticuerpos corresponden al rango de títulos inducidos por vacuna inactivada que usualmente no son títulos altos (Kidd et al., 2006). E1 90\% de caballos de carrera seropositivos evidencia que los caballos fueron vacunados, mientras que la moderada seropositividad detectada en los caballos Peruano de Paso y de equitación podría indicar que no todos los criadores utilizan la vacuna para prevenir esta infección viral.

Los títulos de anticuerpos neutralizantes fueron similares a aquellos detectados en caballos de la provincia de Lima, donde el $65 \%$ presentó títulos entre 2 a 8 y $30 \%$ entre 16 y 64 (Rios et al., 2002). Estos niveles de anticuerpos son detectados en caballos vacunados contra VHE-1 y VHE-4, pero también podría indicar reacciones cruzadas entre VHE-1 y VHE-4 (Paweska et al., 1994) o anticuerpos detectados en estadios tempranos o tardíos, producto de reactivaciones o infecciones naturales (Smith, 1997). Títulos de anticuerpos mayores a 128 , detectados en el $11.9 \%$ de los caballos positivos a anticuerpos contra VHE-1/VHE-4, indican una infección activa o reciente, tal vez producto de reactivaciones o infecciones respiratorias agudas. Es notar que la mayoría de estos casos correspondió a caballos criollos (Cuadro 3).

Respecto a la inmunidad humoral en infecciones herpéticas existen aún divergencias. Algunos autores manifiestan que después de una infección primaria con el VHE-1/ VHE-4, el animal desarrolla anticuerpos neutralizantes que lo protegen contra reinfecciones durante 4 a 8 meses, aunque algunos reportes indican una duración de la protección de menos de 3 meses, lo que significa que el rol protectivo de la IgG no es de larga duración, pudiendo persistir en títulos moderados por un año o más (Van Maanen, 2002; Paillot et al., 2008), siendo entonces la inmunidad celular de mayor relevancia en estas infecciones (Allen et al., 1999).

La prueba de neutralización viral utilizada en el presente estudio es la prueba estándar contra la cual se han estandarizado otras pruebas más sensibles, como las pruebas de ELISA y las moleculares. No existen datos de su especificidad y sensibilidad para el caso de diagnóstico del VHE-1/VHE-4; sin embargo, es una prueba que posee una especificidad del $100 \%$, aunque su sensibilidad puede variar, dependiendo del cultivo celular utilizado como sistema indicador. Esta es una prueba alternativa para el diagnóstico del herpes equino (OIE, 2012).

\section{Conclusiones}

- Se confirma la presencia de los virus causales de la rinoneumonitis equina (VHE-1/VHE-4) en los caballos del país.

- Los anticuerpos neutralizantes contra el VHE-1/VHE-4 tuvieron un rango de 2 a $>256$.

\section{Agradecimientos}

Los autores agradecen a los veterinarios y personal de campo del SENASA que colectaron las muestras de suero de los caballos para el presente estudio.

\section{Literatura Citada}

\section{Allen GP, Kydd JH, Slater JD, Smith}

KC. 1999. Advances in understanding of the pathogenesis, epidemiology, and immunological control of equine herpesvirus abortion. In: Wernery $\mathrm{U}$, Wade JF, Mumford JA, Kaaden OR (eds). Equine infectious diseases. Proc VIII International Conference. Newmarket, England: R\&W Publications. p 129-146. 
2. Berrios PE. 2002. Antecedentes en Chile de enfermedades virales de los animales domésticos. II. Enfermedades de presentación clínica y de alta seroprevalencia. Avan Cienc Vet 17: 3-13.

3. Boelaert F, Biront P, Soumare B, Dispas $M$, Vanopdenbosch $E$, Vermeersch JP, Raskin A, et al. 2000. Prevalence of bovine herpesvirus- 1 in the Belgian cattle population. Prev Vet Med 45: 285-295. doi: 10.1016/S01675877(00)00128-8

4. Borchers $K$, Wolfinger $U$, Ludwing $H$. 1999. Latency-associated transcripts of equine herpesvirus type 4 in trigeminal ganglia of naturally infected horses. $\mathrm{J}$ Gen Virol 80: 2165-2171.

5. Cunha ESM, Ferrari CI, Lara M do CCSH, da Silva LHQ. 2002. Presença de anticorpos contra o herpesvirus eqüino 1 (HVE-1) em eqüinos do noroeste do Estado de São Paulo. Arq Inst Biol 69: $1-5$

6. Daniel W. 1996. Bioestadística: base para el análisis de las ciencias de la salud. $5^{\text {a }}$ ed. México: Uteha Noriega Ed. $878 \mathrm{p}$.

7. Ellis JA, Bodgan JR, Kanara EW, Morley PS, Haines DM. 1995. Cellular and antibody responses to equine herpesviruses 1 and 4 following vaccination of horses with modified-live and inactivated viruses. J Am Vet Med Assoc 206: 823-832.

8. Galosi CM, Norimine J, Echeverría MG, Oliva GA, Nosetto EO, Etcheverrigaray ME, et al. 1998. Diversity of genomic electropherotypes of naturally occurring equine herpesvirus 1 isolates in Argentina. Braz J Med Biol Res 31: 771-774. doi: 10.1590/S0100879X1998000600007

9. Goodman LB, Wimer C, Dubovi EJ, Gold C, Wagner B. 2012. Immunological correlates of vaccination and infection for equine herpesvirus 1 . Clin Vaccine Immunol 19: 235-241. doi: 10.1128/CVI.05522-11
10. Gordon J. 2001. The horse industry. Rural Industries Research \& Development Corporation. [Internet]. Disponible en: http://www.horsecouncil. org.au/ahic/index.cfm/topics/surveys/ the-horse-industry-contributing-to-theaustralian-economy/

11. Goodwin D. 1999. The importance of ethology in understanding the behaviour of the horse. Equine Vet J 28: 15-19. doi: 10.1111/j.2042-3306.1999.tb05150.x

12. Henninger RW, Reed SM, Saville WJ, Allen GP, Hass GF, Kohn CW, Sofaly C. 2007. Outbreak of neurologic disease caused by equine herpesvirus- 1 at a university equestrian center. J Vet Intern Med 21: 157-165. doi: 10.1892/08916640(2007)21[157:OONDCB]2.0.CO;2

13. [INEI] Instituto Nacional de Estadísticas e Informática. 2012. Ministerio de Agricultura y Riego. Lima-Perú. IV Censo Nacional Agropecuario. $62 \mathrm{p}$.

14. Johnson DC, Baines JD. 2011. Herpesviruses remodel host membranes for virus egress. Nat Rev Microbiol 9: 382-394. doi: 10.1038/nrmicro2559

15. Kidd JH, Townsend HGG, Hannant D. 2006. The equine immune response to equine herpes virus-1: The virus and its vaccines. Vet Immunol Immunopathol 111: 15-30. doi: 10.1016/J.vetimm. 2006.01.005

16. [OIE] World Organization for Animal Health. 2008. Manual of diagnostic tests and vaccines for terrestrial animals. Chapter 2.5.9. Equine rhinopneumonitis. p 894-903. [Internet]. Available in: http:/ /www.oie.int/fileadmin/Home/eng/

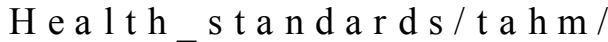
2.05.09_equine_rhino.pdf

17. Paillot R, Case R, Ross J, Newton R, Nugent J. 2008. Equine herpes virus-1: virus, immunity and vaccines. Open Vet Sci J 2: 68-91.

18. Patel JR, Heldens J. 2005. Equine herpesviruses 1 (EHV-1) and 4 (EHV4)-epidemiology, disease and immunoprophylaxis: a brief review. Vet J 170: 14-23. doi: 10.1016/j.tvj1.2004.04.018 
19. Paweska JT, Gerdes T, Van Heerden J. 1994. Serological relationship between a donkey alphaherpesvirus (isolate M7/91) and equid herpesvirus type 1 and 4. J S Afr Vet Assoc 65: 64-66.

20. Pusterla N, Wilson WD, Madigan JE, Ferraro GL. 2009. Equine herpesvirus1 myeloencephalopathy: a review_of recent developments. Vet J 180: 279-289. doi: 10.1016/j.tvj1.2008.08.004

21. Ploszay G, Rola J, Larska M, Zmudzinski JF. 2013. First report on equine herpesvirus type 4 isolation in Poland - evaluation of diagnostic tools. Polish J Vet Sci 16(3): 493-500. doi: 10.2478/pjvs-2013-0069

22. Ríos P, Benito A, Rivera H. 2002. Rinoneumonitis equina en caballos del valle de Lima. Rev Inv Vet Perú 13(2): 66-71.

23. Rivera H, Alvitres R, Manchego A, Sandoval N, Rosadio R. 1997. Aborto por virus herpes equino. Rev Inv Pec IVITA 8(1): 49-55.

24. Ruíz-Sáenz J, Góez Y, UrcuquiInchima $S$, Góngora A, López A. 2008. Serologic evidence of equine herpesvirus 1 and 4 infection in two regions of Colombia. Rev Colom Cienc Pecua 21: 251-258.

25. Segura JC, Honhold N. 2000. Métodos de muestreo para la producción y la salud animal. Yucatán, México: Universidad Autónoma de Yucatán. 160 p.
26. [SENASA] Servicio Nacional de Sanidad Agraria. 2013. Documento sustentatorio para la declaración del Perú como país libre de Arteritis Viral Equina, Durina y Muermo. Lima: SENASA. 51 p. [Internet] Disponible en: http:// www.senasa.gob.pe/senasa/wp-content/ uploads/jer/equidos/Declaracion $\% 20$ Peru\%20Libre\%20de\%20AVE _Durina_Muermo.pdf

27. Smith KC. 1997. Herpesviral abortion in domestic animals. Vet J 153: 253-268. doi: 10.1016/S1090-0233(97)80061-5

28. Van Maanen C, Willink DL, Smeenk LA, Brinkhof J, Terpstra C. 2000. An equine herpesvirus 1 (EHV1) abortion storm at a riding school. Vet Q 22: 8387. doi: 10.1080/01652176.2000.9695030

29. Van Maanen C. 2002. Equine herpesvirus 1 and 4 infections: an update. Vet Q 24: 58-78. doi: 10.1080/ 01652176.2002 .9695126

30. Van Oirschot JT, Kaashoek MJ, Rijsewijk FA. 1996. Advances in the development and evaluation of bovine herpesvirus 1 vaccines. Vet Microbiol 53: 43-54.

31. Walter J, Seeh, Fey K, Bleul U, Osterrieder N. 2013. Clinical observations and management of a severe equine herpesvirus type 1 outbreak with abortion and encephalomyelitis. Acta Vet Scand 55: 19. doi:10.1186/1751-0147-55-19 